\title{
Use of plasma levels in evaluation of procainamide dosage
}

\author{
T. R. D. Shaw, C. R. Kumana, R. B. Royds, C. M. Padgham, and John Hamer \\ From the Department of Cardiology and Department of Clinical Pharmacology, \\ St. Bartholomew's Hospital, London
}

Plasma procainamide levels achieved by oral procainamide treatment were studied in patients with recent myocardial infarction or ischaemia. Procainamide therapy was started after intravenous lignocaine had been used to control ventricular arrhythmias in the acute phase. A I g loading dose did not provoke toxicity and achieved 4-hour levels in or near the therapeutic range in 79 per cent of patients. Some patients with cardiac failure absorbed oral procainamide very slowly. A maintenance regimen of $375 \mathrm{mg} 4$ hourly failed to maintain effective procainamide levels in 73 per cent of patients. On a dosage of $500 \mathrm{mg} 4$ hourly 36 per cent had ineffective levels before each dose. Measurement of procainamide levels is desirable during treatment, since the variation between patients given a standard dosage is considerable and unpredictable. To maintain adequate procainamide levels frequent doses are necessary but inconvenient.

Ventricular arrhythmias are very common in the first few days after myocardial infarction and are a major cause of death. There is also a significant incidence of arrhythmias in the weeks and months after infarction (Norris et al., 1968; Denborough et al., 1968; Lawrie, 1969; Sloman et al., 1970). Intravenous lignocaine is helpful in the first few days, but no entirely satisfactory drug regimen has been established to prevent these later arrhythmias which occur at a time when oral treatment would be more appropriate. Procainamide has been shown to provide effective prophylaxis against ventricular arrhythmias during the acute phase of infarction (Koch-Weser et al., 1969). It is usually well absorbed when taken orally (Mark et al., 1951 ; KochWeser, 197I) and is thus a feasible drug for longer term management after intravenous treatment is ended.

In this study procainamide was administered to patients who had developed ventricular arrhythmias requiring treatment with lignocaine in the immediate postinfarction period. Procainamide was started at the end of the lignocaine infusion period and was continued during convalescence in the general wards.

Koch-Weser and colleagues (Koch-Weser et al., 1969; Koch-Weser and Klein, I97I) have shown that the effectiveness of procainamide is closely related to the plasma concentration attained and they established the ranges associated with effectiveness and toxicity. They found that plasma levels of $4-8 \mu \mathrm{g} / \mathrm{ml}$ Received 12 September 1973. successfully suppressed ventricular arrhythmias in the great majority of patients and were rarely associated with toxicity.

We have measured the plasma procainamide levels achieved with procainamide treatment during the hospital convalescent period.

\section{Patients and methods}

All the patients studied had been admitted to a coronary care unit. Myocardial infarction or ischaemia had been diagnosed on the basis of clinical history, electrocardiograms, and serial estimations of cardiac enzymes. Left heart failure was judged to be present if characteristic features were present in the chest $x$-ray.

In each case a ventricular arrhythmia had been observed during monitoring and treated by lignocaine. In a few cases additional antiarrhythmic drugs had been required. Arrhythmias classified as requiring lignocaine therapy were: ventricular fibrillation, ventricular tachycardia, and ventricular ectopic beats which were multifocal, ' $R$ on $T$ ', in a sequence of 2 or more, or occurring more frequently than 5 a minute. Ventricular arrhythmias associated with a slow sinus rate and abolished by atropine were not included in this classification.

\section{Procainamide dosage}

Procainamide therapy was started at dosages that were based on body weight. Patients weighing 50-90 kg were given a loading dose of $\mathrm{I} \mathrm{g}$ followed 4 hours later by maintenance doses of $375 \mathrm{mg}$ every 4 hours throughout the day and night. The maintenance dose was subse- 
quently increased or decreased if indicated by clinical response or recorded plasma procainamide level. The I $\mathbf{g}$ oral loading dose was given at II.00 hours: this was 3 hours after a light breakfast and I hour before lunch. The lignocaine infusion was stopped about I hour after the loading dose had been given. The average time between admission and start of procainamide was 4.7 days (range 2-24).

The majority of patients were transferred to the general medical wards within 24 hours of the start of procainamide administration.

Blood for plasma procainamide estimation was taken at $I$ and 4 hours after the loading dose. In 5 patients samples were taken at 15-minute intervals for the first 2 hours, then half-hourly during the second 2 hours. During maintenance therapy samples were taken at 15.00 hours, 4 hours after the previous dose.

A tablet formulation of procainamide was used ('Pronestyl': Squibb).

\section{Plasma procainamide assay}

Procainamide concentrations in plasma were determined spectrophotofluorometrically by the method of Mark et al. (195I), modified by D. C. Hicks (I97I, personal communication). All samples were determined in duplicate.

The accuracy of the method was assessed by blind estimation of samples to which a known amount of procainamide had been added. Assays of samples containing $4.0,5.0$, and $7.5 \mu \mathrm{g} / \mathrm{ml}$ gave mean levels $( \pm S D$ ) of $4.33 \pm 0.08,5.26 \pm 0.05$, and $7.35 \pm 0.05 \mu \mathrm{g} / \mathrm{ml}$, respectively. The metabolites para-aminobenzoic acid and paraacetobenzoic acid were tested and found not to interfere. Lignocaine and heparin were not detected by the assay. Recovery of procainamide by the extraction process was IOO per cent.

All plasma levels are expressed as procainamide base.

\section{Results}

\section{Absorption curves}

Fig. I shows the plasma procainamide levels recorded at frequent intervals after a I $\mathbf{g}$ dose. Peak levels

TABLE Age, body weight, and blood urea (means $\pm S D$ ) of patients receiving procainamide

\begin{tabular}{|c|c|c|c|}
\hline Group & $\begin{array}{l}\text { Age } \\
(y r)\end{array}$ & $\begin{array}{l}\text { Body } \\
\text { weight (kg) }\end{array}$ & $\begin{array}{l}\text { Blood urea } \\
(\mathrm{mg} / \mathrm{roO} \mathrm{ml})\end{array}$ \\
\hline \multicolumn{4}{|l|}{$\begin{array}{l}\text { Loading dose } \\
\text { patients }\end{array}$} \\
\hline $\begin{array}{l}\mathrm{N}=43 \\
375 \mathrm{mg} \text { per } 4 \text {-hour } \\
\text { maintenance } \\
\text { dosage }\end{array}$ & $57 \cdot 0 \pm 8 \cdot 1$ & $70 \cdot 8 \pm 8 \cdot 5$ & $44 \pm 20$ \\
\hline $\begin{array}{l}\mathrm{N}=22 \\
500 \mathrm{mg} \text { per } 4 \text {-hour } \\
\text { maintenance } \\
\text { dosage }\end{array}$ & $57 \cdot 4 \pm 8 \cdot 3$ & $70 \cdot 1 \pm 9 \cdot 6$ & $42 \pm 20$ \\
\hline $\mathrm{N}=14$ & $51 \cdot 5 \pm 7 \cdot 6$ & $8 I \cdot 9 \pm 12 \cdot 0$ & $43 \pm 14$ \\
\hline
\end{tabular}

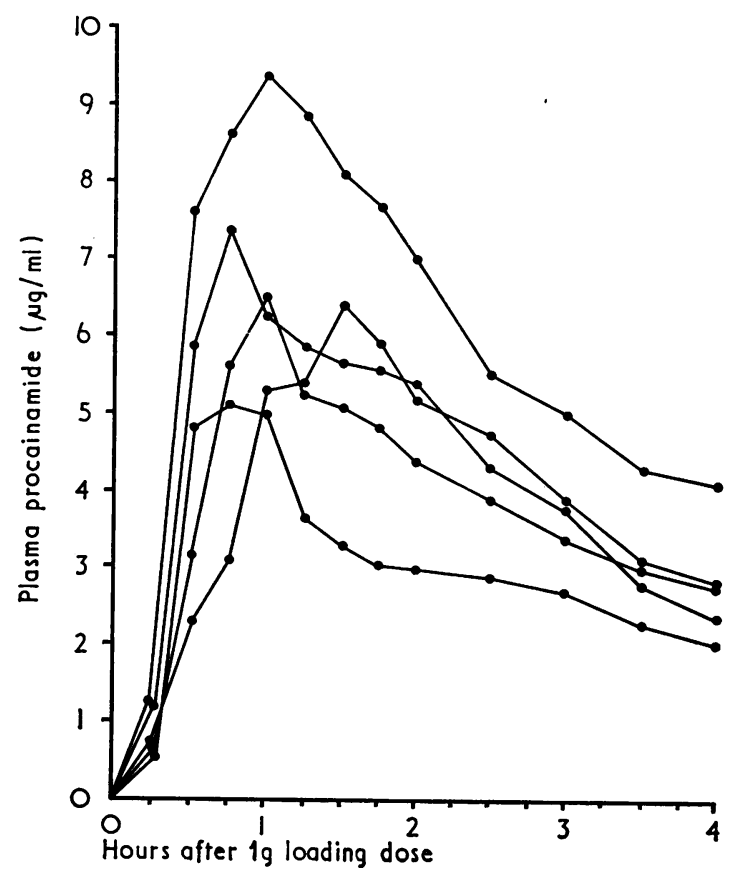

FIG. I Plasma procainamide levels recorded at frequent intervals after a I $g$ loading dose (5 patients).

occurred at 45 to 90 minutes. When absorption was rapid, producing high peak levels, the I-hour reading closely approximated the maximal level.

\section{Loading dose}

Plasma procainamide levels at I and 4 hours after a I $\mathrm{g}$ loading dose were recorded in 43 patients and are shown in Fig. 2. The characteristics of these patients are given in the Table. The mean level at I hour was $6.17 \mu \mathrm{g} / \mathrm{ml}(S D \pm 0.84)$. Seven patients had a procainamide level greater than $8 \mu \mathrm{g} / \mathrm{ml}$ but no clinical or electrocardiographic evidence of toxicity was seen in these patients. At 4 hours, 16 patients $(37 \%)$ were still within the 'effective' range of 4 to $8 \mu \mathrm{g} / \mathrm{ml}$ and 18 patients $(42 \%)$ had a level between 3.0 and $3.9 \mu \mathrm{g} / \mathrm{ml}$.

In 5 patients (12\%) the 4-hour level was higher than the I-hour level, indicating very slow absorption of the drug. Each of these 5 patients had mild or moderate cardiac failure. However, some patients with equal or more severe degrees of failure had absorbed the drug rapidly. To assess the effect of cardiac failure on absorption the plasma levels in patients with and without cardiac failure were analysed separately. In 18 patients without failure , the $\mathrm{I}$ - and 4-hour levels were $7.06(\mathrm{SE} \pm 0.3 \mathrm{I})$ and 


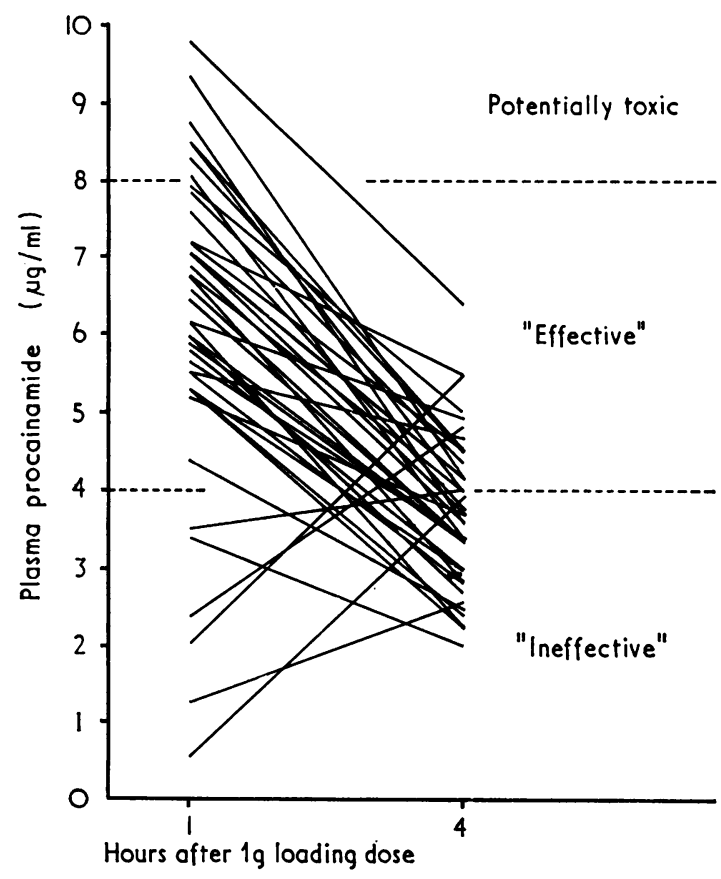

FIG. 2 Plasma procainamide levels at $I$ and 4 hours after a I $\mathrm{g}$ loading dose given to 43 patients weighing 50 to $90 \mathrm{~kg}$.

$3.53(\mathrm{SE} \pm 0.14) \mu \mathrm{g} / \mathrm{ml}$, respectively: in 20 patients with cardiac failure the levels were 5.23 (SE \pm 0.54$)$ and $3.83(\mathrm{SE} \pm 0.25)$. The difference in the 1 -hour levels is statistically significant $(P<0.01$, Student's $t$ test). These differences in I- and 4-hour levels indicate that cardiac failure tends to slow the rate of absorption. Four patients who had been slow absorbers of procainamide were investigated again after discharge from hospital when all were free of cardiac failure at rest. Only I still showed a delay in procainamide absorption.

\section{Maintenance dosage}

Plasma procainamide concentration after 24 hours of maintenance therapy of $375 \mathrm{mg} 4$ hourly was measured at 4 hours after the last dose in 22 patients (Fig. 3). The mean level was $3.47 \mu \mathrm{g} / \mathrm{ml}(S D \pm \mathrm{r} \cdot 24)$. Only 6 subjects $(27 \%)$ had a level greater than $4 \mu \mathrm{g} /$ $\mathrm{ml}$. Fourteen patients had used a dosage of 500 mg 4 hourly: 5, whose weight exceeded $90 \mathrm{~kg}$, started treatment at this dosage level. The levels obtained 4 hours after the previous dose are also shown in Fig. 3. Nine patients $(64 \%)$ had a level within the 'effective' range of 4 to $8 \mu \mathrm{g} / \mathrm{ml}$. The mean level with this dosage was 4.46 ( $S D \pm \mathrm{I} \cdot 49)$.

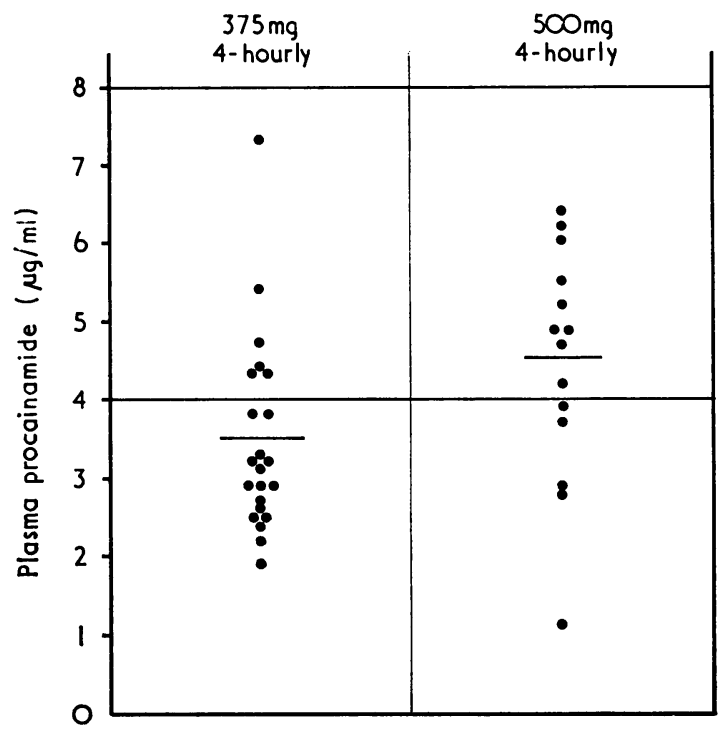

FIG. 3 Plasma procainamide levels after 24 hours of maintenance therapy at $375 \mathrm{mg} / 4$ hours and $500 \mathrm{mg} / 4$ hours. Levels were recorded 4 hours after the last dose. The bars represent the mean levels.

The personal data of these patients are included in the Table. There was a wide range of levels attained in patients using the same dosage.

There was a weak and statistically insignificant correlation between the 4-hour procainamide level

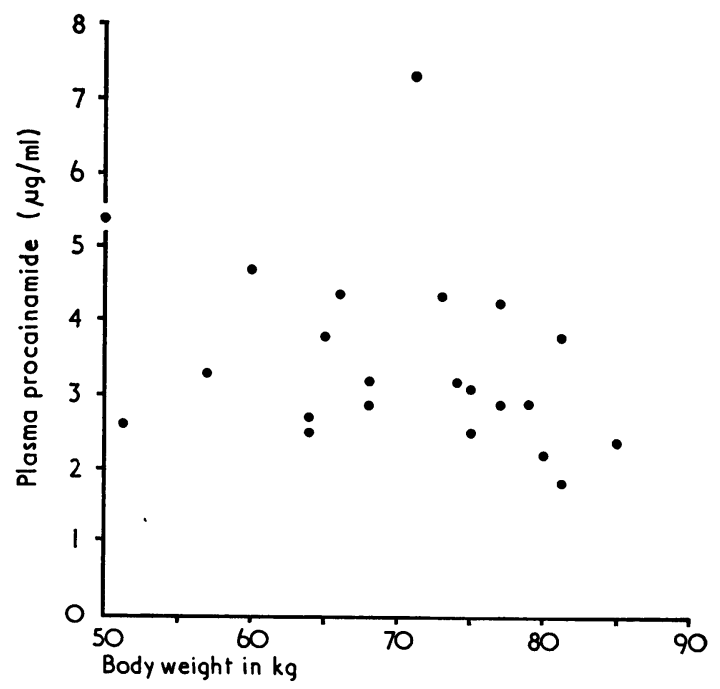

FIG. 4 Relation between body weight and plasma procainamide level recorded before the next dose after 24 hours of maintenance therapy at $375 \mathrm{mg} / 4$ hours. 
therapy and the body weight (Fig. 4). This was also the case when patients with raised blood urea were excluded. There was also a poor correlation between the procainamide level and the blood urea.

Fig. 5 shows the plasma procainamide levels recorded on consecutive days during maintenance therapy at a constant dosage. Dosages for individual patients ranged from 250 to $500 \mathrm{mg}$ every 4 hours. For clarity the levels showing an increase have been plotted separately from those showing a decrease. In I6 of the I9 patients the level changed only slightly but in 3 a pronounced change in drug level was recorded (Patients A, B, and C in Fig. 5). Patient C had a second myocardial infarction I5 hours after the first level was recorded and developed cardiogenic shock with a low output of urine. The dosage of procainamide had not been altered and the increase in level reflects altered distribution and excretion of the drug. With patients A and B the low level was due to failure of administration of doses.

Twelve patients had the plasma procainamide concentration measured before their next dose after both 24 hours and 5 to 9 days of a constant dosage of $375 \mathrm{mg} 4$ hourly. The mean levels were similar at $3.73(\mathrm{SD} \pm \mathrm{I} \cdot \mathrm{I} 4)$ and $4.07(\mathrm{SD} \pm 2 \cdot 09) \mu \mathrm{g} / \mathrm{ml}$, respectively.

\section{Discussion}

It is often necessary in treatment to adjust the dosage of a drug until the desired response in the individual patient is achieved. However, outside coronary care units, ventricular tachycardia and fibrillation are often fatal and 'titration' of the antiarrhythmic drug dosage for each patient may not be possible. In this situation it is desirable to know from the outset that the dosage has produced satisfactory drug levels in the blood and tissues.

Measurement of plasma drug concentration is useful during the administration of procainamide as there is wide variation in the levels obtained with the same dosage (Koch-Weser, 1972). The pronounced differences exist even when allowances are made for individual body weight and renal function KochWeser, 197I). Furthermore, the amount of drug in the body may alter rapidly if there is a change in the clinical condition which modifies the handling of the drug. Our results confirm the existence of pronounced variation between patients in the plasma levels of procainamide produced by a standard dosage, and suggest that it is partly due to differences in the rate of absorption of the drug. Slow absorption appears more likely to occur with cardiac failure and can become normal when failure is no longer present.

Knowledge of plasma drug concentration is of little value in prophylactic therapy unless there are established ranges known to correspond to satisfactory clinical effect and to toxicity. The 'effective' range is never absolute but indicates the values at which a successful response is obtained in a majority of patients. On the basis of a wide experience of the use of procainamide and measurement of plasma levels, Koch-Weser and co-workers proposed an 'effective' range of 4 to $8 \mu \mathrm{g} / \mathrm{ml}$ (Koch-Weser et al., 1969; Koch-Weser and Klein, 197I); in their patients procainamide toxicity was rarely seen with these levels but became progressively more common with values greater than $8 \mu \mathrm{g} / \mathrm{ml}$ and was the rule with levels near $16 \mu \mathrm{g} / \mathrm{ml}$. Levels of 2 to 4 $\mu \mathrm{g} / \mathrm{ml}$ suppressed arrhythmias in only half of their patients. Giardina, Heissenbuttel, and Bigger (1973) found a similar range of effective plasma concentration when ventricular arrhythmias were abolished by repeated intravenous doses of procainamide.

An oral loading dose of $\mathrm{I} g$ appears to be a satisfactory one to follow lignocaine infusions. Only 16 per cent of the patients exceeded $8 \mu \mathrm{g} / \mathrm{ml}$ at $\mathrm{I}$ hour and none was noted to develop toxicity. At 4 hours after the loading dose a third of the patients still had levels within the 'effective' range and nearly 80 per cent had a level above $3 \mu \mathrm{g} / \mathrm{ml}$. For most patients effective levels were achieved within an hour, but in some absorption was slow and there was a delay before a level within the effective range was reached. However, these patients had cardiac failure and absorption of an intramuscular dose can also be delayed when cardiac output is low (Koch-Weser et al., 1969). The combination of lignocaine and procainamide did not appear to produce any adverse effect and it seems worth while to continue the lignocaine infusion for an hour after the loading dose to cover the period before effective procainamide levels are reached.

The maintenance dosage regimen of $375 \mathrm{mg} 4$ hourly (2.25 $\mathrm{g}$ per day) provided 4 -hour procainamide levels within the 4 to $8 \mu \mathrm{g} / \mathrm{ml}$ range in only 23 per cent of the patients. Collste et al. (1972) have also reported low plasma levels with this dose. A dosage of $500 \mathrm{mg}$ every 6 hours (2.0 $\mathrm{g}$ a day) would have produced even lower levels before each dose. Kosowsky et al. (1973) have found very low levels in outpatients on long-term procainamide therapy at a dosage of $500 \mathrm{mg}$ every 6 to 8 hours. These dosages appear to be too small even for the initiation of procainamide therapy. We conclude that $500 \mathrm{mg}$ every 4 hours would be a reasonable regimen to begin the maintenance period. With regular administration of a fixed dose of a drug the amount present in the body during the dosing interval eventually reaches a constant value, representing * equilibrium between the drug intake and excretion. 


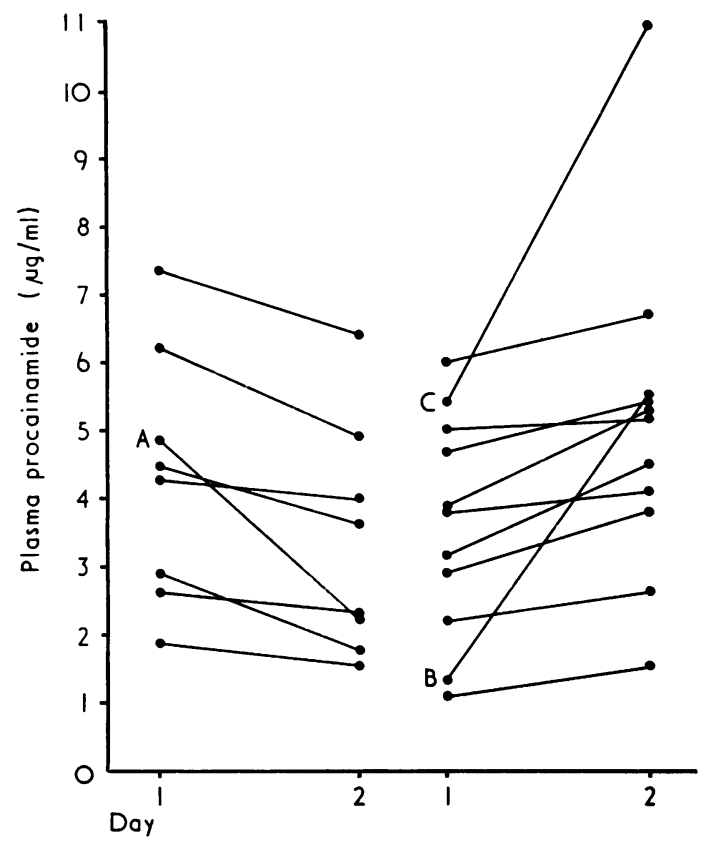

FIG. 5 Plasma procainamide levels recorded on consecutive days during maintenance therapy at a constant dosage. Levels showing an increase on the second day have been plotted separately from those showing a decrease. (Patients $A, B$, and $C$ : see text.)



FIG. 6 Diagrammatic representation of the diffculties in formulating a satisfactory procainamide dosage regimen when absorption is rapid. Absorption and distribution were assumed to be complete at I hour and the elimination half-life has been taken to be 3.5 hours. (A) If a dosage produces a I-hour level just below the potentially toxic range, then ineffective levels are reached at 6 and 8 hours if no further maintenance dose has been given. (B) If the dosage is increased to provide an effective level at 6 hours, the $I$ hour level is within the potentially toxic range.
The time to reach this 'steady state' depends on the elimination rate of the drug. With procainamide this steady state will be reached within 24 hours by most patients: those with very delayed procainamide excretion may require up to 48 hours. The procainamide level should be measured after I or 2 days administration and the dosage then adjusted if necessary to individual needs.

A major disadvantage of procainamide is its rapid elimination from the body. In subjects with normal renal function its mean half-life is approximately 3.5 hours (Koch-Weser, 197I). Fig. 6 illustrates the dilemma in formulating an oral dosage regimen for such a short acting drug when absorption is rapid. If the total daily dose is kept constant but the interval between doses prolonged, ineffective plasma levels are reached before the next dose. If the dosage interval is constant but the size of each dose increased to avoid low concentrations, then the consequently higher peak levels may cause toxicity if, like procainamide (Koch-Weser, 197I), the drug is rapidly distributed to the tissues. To keep the drug levels within the relatively narrow effective range it becomes necessary to administer doses at very frequent intervals. Koch-Weser et al. (1969) have used a 3-hourly administration regimen but we felt this was unsuitable for use in the convalescent period. Even with a 4-hourly regimen, we had initially found it very difficult to ensure regular administration of doses in general medical wards. The importance of accurately timed doses was emphasized to ward staff and the regularity of administration had greatly improved by the time this study began. However, a 4-hourly regimen is vulnerable to disruption by the patient's absence from the ward, e.g. for $x$-rays, and many patients found that the night time procainamide dose disturbed their sleep to a troublesome extent. We now consider a 4-hourly regimen unsatisfactory for routine prophylactic use. The use of procainamide would be improved if a satisfactory slow release preparation was available or if a chemical modification could be made to prolong the half-life of elimination. At present the frequent administration of adequate doses based on plasma drug level measurements is the surest way of maintaining a satisfactory antiarrhythmic effect.

\section{References}

Collste, P., Karlsson, E., Norlander, B., Sievers, J., and Sjögvist, F. (1972). Arytmiprofylax med prokainamid: inadekvat dosering ? Läkartidningen, 69, Suppl. 2, 47.

Denborough, M. A., Lovell, R. R. H., Nestel, P. J., and Goble, A. J. (1968). Arrhythmias and late sudden death after myocardial infarction. Lancet, $1,386$.

Giardina, E.-G. V., Heissenbuttel, R. H., and Bigger, J. T. (1973). Intermittent intravenous procaine amide to treat 
ventricular arrhythmias: correlation of plasma concentration with effect on arrhythmia, electrocardiogram, and blood pressure. Annals of Internal Medicine, 78, 183.

Koch-Weser, J. (1971). Pharmacokinetic of procainamide in man. Annals of the New York Academy of Sciences, 179, 370.

Koch-Weser, J. (1972). Drug therapy. Serum drug concentrations as therapeutic guides. New England fournal of Medicine, 287, 227.

Koch-Weser, J., and Klein, S. W. (1971). Procainamide dosage schedules, plasma concentrations, and clinical effects. Fournal of the American Medical Association, 215, I454.

Koch-Weser, J., Klein, S. W., Foo-Canto, L. L., Kastor, J. A., and DeSanctis, R. W. (1969). Antiarrhythmic prophylaxis with procainamide in acute myocardial infarction. New England fournal of Medicine, 281, 1253.

Kosowsky, B. D., Taylor, J., Lown, B., and Ritchie, R. F. (1973). Long term use of procaine amide following acute myocardial infarction. Circulation, 47, 1204.

Lawrie, D. M. (1969). Long-term survival after ventricular fibrillation complicating acute myocardial infarction. Lancet, 2, 1085.

Mark, L. C., Kayden, H. J., Steele, J. M., Cooper, J. R., Berlin, I., Rovenstine, E. A., and Brodie, B. B. (I95I). The physiological disposition and cardiac effects of procaine amide. Fournal of Pharmacology and Experimental Therapeutics, 102, 5.

Norris, R. M., Bensley, K. E., Caughey, D. E., and Scott, P. J. (1968). Hospital mortality in acute myocardial infarction. British Medical fournal, 3, 143.

Sloman, G., Dowling, J., Thompson, P., Hunt, D., Brown, R., and Ferguson, J. (1970). Prevalence of malignant arrhythmias in acute myocardial infarction. In Symposium on Cardiac Arrhythmias, p. 677. Edited by E. Sandøe, E. Flensted-Jensen, and K. H. Olesen. Astra, Södertälje, Sweden.

Requests for reprints to Dr. T. R. D. Shaw, Department of Cardiology, St. Bartholomew's Hospital, London ECIA 7 BE. 